\title{
Quantification of Antioxidant Phenolic Compounds in a New Chrysanthemum Cultivar by High-Performance Liquid Chromatography with Diode Array Detection and Electrospray Ionization Mass Spectrometry
}

\author{
Ah-Reum Han, ${ }^{1}$ Hyo Young Kim, ${ }^{1}$ Yangkang So, ${ }^{1}$ Bomi Nam, ${ }^{1,2}$ \\ Ik-Soo Lee, ${ }^{2}$ Joo-Won Nam, ${ }^{3}$ Yeong Deuk Jo, ${ }^{1}$ Sang Hoon Kim, ${ }^{1}$ \\ Jin-Baek Kim, ${ }^{1}$ Si-Yong Kang, ${ }^{1}$ and Chang Hyun Jin ${ }^{1}$ \\ ${ }^{1}$ Advanced Radiation Technology Institute, Korea Atomic Energy Research Institute, Jeongeup-si, Jeollabuk-do 56212, \\ Republic of Korea \\ ${ }^{2}$ College of Pharmacy, Chonnam National University, Gwangju 11686, Republic of Korea \\ ${ }^{3}$ College of Pharmacy, Yeungnam University, Gyeongsan-si, Gyeongsangbuk-do 38541, Republic of Korea
}

Correspondence should be addressed to Ah-Reum Han; arhan@kaeri.re.kr

Received 14 March 2017; Revised 12 April 2017; Accepted 3 May 2017; Published 24 May 2017

Academic Editor: Shaoping Li

Copyright (C) 2017 Ah-Reum Han et al. This is an open access article distributed under the Creative Commons Attribution License, which permits unrestricted use, distribution, and reproduction in any medium, provided the original work is properly cited.

The flowers of Chrysanthemum morifolium Ramat. have been used as an herbal tea and in traditional medicine, and the plant has been developed to produce horticultural cultivars of various colors and shapes. In this study, a new chrysanthemum cultivar with dark purple petals (C. morifolium cv. ARTI-Dark Chocolate; ADC) was developed by radiation-induced mutation breeding of its original cultivar with purple striped white petals (C. morifolium cv. Noble Wine, NW). The phenolic profile and antioxidant property of ADC were investigated and compared with NW and the commercially available medicinal herb, C. morifolium with yellow petals (CM), in order to find a scientific support to produce a new source of natural antioxidant. Flavonoid and phenolic acid profiles of the ethanol extracts of the three flowers were analyzed by high-performance liquid chromatography-diode array detector-electrospray ionization mass spectrometry (HPLC-DAD-ESIMS), while antioxidant properties were evaluated using the 1,1-diphenyl-2-picryl-hydrazyl (DPPH) and 2,2-azino-bis-3-ethylbenzothiazoline-6-sulfonic acid (ABTS) radical scavenging assay. Among the tested flowers, ADC possessed the strongest antioxidant capacity and the highest phenolic contents. Flavonoids (acacetin, apigenin, luteolin, acacetin-7-O- $\beta$-glucoside, apigenin-7-O- $\beta$-glucoside, luteolin-7-O- $\beta$-glucoside, and linarin) and phenolic acids (chlorogenic acid and mixture of 1,4-, 1,5-, and 3,5-dicaffeoylquinic acids) were identified and quantified.

\section{Introduction}

The dried flowers of Chrysanthemum morifolium Ramat. (Compositae), known as Chrysanthemi Flos, have been used as an infusion tea and in traditional medicine to treat inflammation, arteriosclerosis, and hypertension [1]. In previous phytochemical studies on C. morifolium, flavonoids and phenolic acids have been identified as major constituents [2], which have exhibited diverse biological activities such as antioxidant [3], anti-inflammatory [4], and antitumor effects [5].
Numerous varieties and cultivars have been developed by hybridization and mutation for horticultural purposes [6] and to improve crop productivity and quality [7]. Mutation is widely used in plant breeding research and generated by spontaneous mutation, ultraviolet lights, chemical mutagens, and ionizing radiation (i.e., X-rays and gamma-rays) [7]. More than 3,000 mutant varieties of plants have been registered with the Food and Agriculture Organization/International Atomic Energy Agency (FAO/ IAEA), most of which were developed with gammairradiation (available online at http://mvd.iaea.org). Recently, 


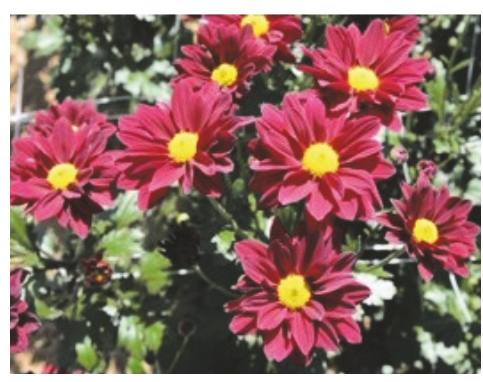

(a)

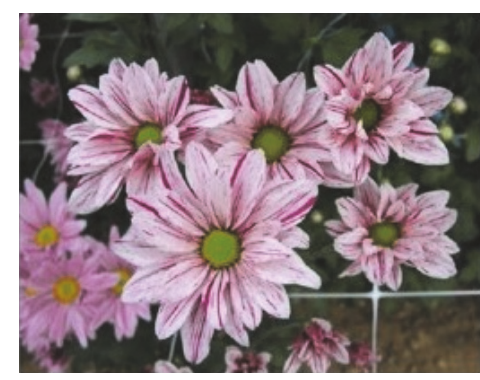

(b)

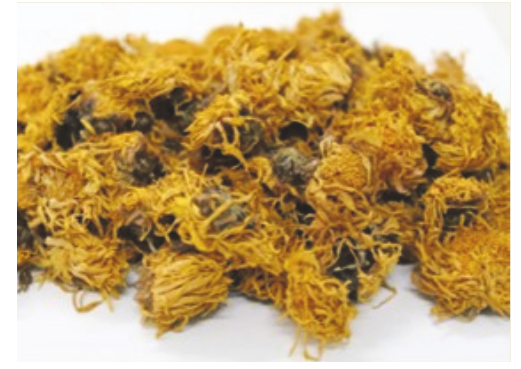

(c)

FIgURE 1: The flowers of (a) a radiation-induced mutant cultivar, C. morifolium cv. ARTI-Dark Chocolate (ADC); (b) the original cultivar, C. morifolium cv. Noble Wine (NW); (c) the commercially available medicinal herb, C. morifolium (CM).

our research group has developed a new chrysanthemum cultivar, C. morifolium cv. ARTI-Dark Chocolate (ADC), by gamma-irradiation on stem cuttings of the chrysanthemum cultivar, C. morifolium cv. Noble Wine (NW), and registered a new plant variety (registration number 4996) in the Korea Seed and Variety Service (available online at https://www.seed.go.kr/english/function/system_06.jsp) (Figure 1).

As part of our ongoing search for functional resources from new cultivars developed by radiation-induced mutation breeding, we assessed a $95 \%$ ethanol extract of the flowers of ADC. The extract showed higher antioxidant activity in the DPPH and ABTS radical scavenging assays than did extracts of the original cultivar, NW, and the commercially available medicinal herb C. morifolium with yellow petals (CM). Therefore, the ethanol extract was subjected to bioactivity-guided fractionation, leading to the isolation of seven flavonoids. In addition to the flavonoids isolated, four phenolic acids were found to be the constituents of the flowers of ADC by HPLC-DAD-ESIMS analysis. To identify the differences in the phytochemical contents of the three flowers depending on their activities, HPLC-DAD-ESIMS analysis was performed on standards and samples of the $95 \%$ ethanol extracts of each of the flowers.

\section{Materials and Methods}

2.1. General. The $1 \mathrm{D}$ NMR experiment was performed on a JNM-ECA 500 MHz NMR instrument (JEOL, Ltd., Tokyo, Japan). Thin-layer chromatographic (TLC) analysis was performed on Kieselgel 60 F254 (Merck, Darmstadt, Germany), with visualization performed under UV light (254 and $365 \mathrm{~nm}$ ) and $10 \%(\mathrm{v} / \mathrm{v})$ sulfuric acid spray followed by heating $\left(200^{\circ} \mathrm{C}, 2 \mathrm{~min}\right)$. Silica gel (230-400 mesh, Merck), YMC Gel ODS-A (12 nm, S-150 $\mu \mathrm{m}$; YMC Co., Kyoto, Japan), and Sephadex LH-20 (Pharmacia Co., Uppsala, Sweden) were used for column chromatography (CC). Analytical highperformance liquid chromatography-diode array detectorelectrospray ionization mass spectrometry (HPLC-DADESIMS) was carried out on an Agilent 1200 series system and an Agilent 6120 quadrupole MS system (Agilent Technologies Co., Santa Clara, CA, USA) equipped with a YMC-Triart C18 column $(5 \mu \mathrm{m}, 250 \mathrm{~mm} \times 4.6 \mathrm{~mm}$,
YMC Co.). Preparative HPLC was performed on a Gilson Preparative HPLC system (Gilson Inc., Middleton, WI, USA) equipped with YMC Pack Pro C18 (5 $\mu \mathrm{m}, 250 \mathrm{~mm} \times$ $20 \mathrm{~mm}$, YMC Co.). A [ $\left.{ }^{60} \mathrm{Co}\right] \gamma$-irradiator $(150 \mathrm{TBq}$ capacity; ACEL, Ontario, Canada) was used for gamma-irradiation. The standard compounds chlorogenic acid, 1,4- dicaffeoylquinic acid (DCQA), and 4,5-DCQA were purchased from Wuhan ChemFaces Biochemical Co., Ltd. (Hubei, China). 1,3-, 1,5-, 3,4-, and 3,5-DCQAs were purchased from Chengdu Biopurify Phytochemicals Ltd. (Chengdu, China). 2,2-Diphenyl-1-picrylhydrazyl (DPPH), 2,20-azinobis(3-ethylbenzthiazoline-6-sulphonic acid) (ABTS), and ascorbic acid were obtained from Sigma Chemical Co. (St. Louis, MO, USA). All other chemicals and solvents used in this study were of analytical grade.

2.2. Plant Material. C. morifolium cv. ARTI-Dark Chocolate was produced in the same manner described by Jo et al. [8]. $C$. morifolium cv. ARTI-Dark Chocolate with dark purple petals was developed by $50 \mathrm{~Gy}$ gamma-irradiation from a labeled Cobalt $\left({ }^{60} \mathrm{Co}\right)$ source on stem cuttings of C. morifolium $\mathrm{cv}$. Noble Wine, which is a spray-type chrysanthemum cultivar that has white petals with purple stripes. And then, ADC flowers were selected according to petal-color variants and were examined to be of stable inheritance of phenotype for four years (2009-2012). ADC has been grown by Drs. Y. D. Jo, S. H. Kim, J.-B. Kim, and S.-Y. Kang and has been registered as a new plant variety in the Korea Seed and Variety Service (April 2014). ADC and NW flowers were handpicked and randomly collected at the stage of fully openflowering with open dick flowers in the same plantation, in October 2015. The flowers were then freeze-dried, ground, and finally stored at $-20^{\circ} \mathrm{C}$ in polyethylene plastic bags until further analysis. Dried flowers of C. morifolium with yellow petals, which are used for a medicinal herb, were purchased from the Jewondang herb shop in Jeongeup-si, Jeollabuk-do, Korea. The voucher specimens have been deposited at the Advanced Radiation Technology Institute, Korea Atomic Energy Research Institute.

2.3. Extraction and Isolation. The dried flowers of ADC ( $2 \mathrm{~kg})$ were extracted with $95 \% \mathrm{EtOH}(3 \times 30 \mathrm{~L})$ overnight at room temperature. The solvent was evaporated in vacuo to afford 
a 95\% EtOH extract (200 g), which was then suspended in distilled water $(2 \mathrm{~L})$ and partitioned with $n$-hexane $(3 \times 2 \mathrm{~L})$, $\mathrm{CHCl}_{3}(3 \times 2 \mathrm{~L})$, EtOAc $(3 \times 2 \mathrm{~L})$, and $n-\mathrm{BuOH}(3 \times 2 \mathrm{~L})$, sequentially. The EtOAc-soluble fraction $(8 \mathrm{~g})$ was subjected to silica gel column chromatography (CC) $\left(\mathrm{CHCl}_{3}-\mathrm{MeOH}\right.$, $10: 0$ to $1: 9, \mathrm{v} / \mathrm{v})$ to yield fifteen fractions (F01-F15). Fraction F06 (200 mg), eluted with $\mathrm{CHCl}_{3}-\mathrm{MeOH}(98: 2)$ from the first separation, was subjected to Sephadex LH-20 CC $(100 \% \mathrm{MeOH})$ to give four subfractions (F0601-F0604). Subfraction F0604 (19.5 mg) was separated by preparative HPLC (YMC-Triart C18, $\mathrm{CH}_{3} \mathrm{CN}$-water, $1: 1$, v/v, $4 \mathrm{~mL} / \mathrm{min}$, UV $280 \mathrm{~nm})$ to afford $1\left(t_{\mathrm{R}} 20.5 \mathrm{~min}, 3.5 \mathrm{mg}\right)$ and $2\left(t_{\mathrm{R}}\right.$ $40.2 \mathrm{~min}, 5.3 \mathrm{mg}$ ). Fraction F08 (500 mg) was subjected to silica gel CC $\left(\mathrm{CHCl}_{3}-\mathrm{MeOH}, 95: 5\right.$ to $\left.9: 1, \mathrm{v} / \mathrm{v}\right)$ to yield eight fractions (F0801-F0808). Subfraction F0807 (32.5 mg) was chromatographed on a Sephadex LH-20 (100\% MeOH), providing 3 (25.0 mg). Fraction F10 (994 mg) was subjected to silica gel $\mathrm{CC}\left(\mathrm{CHCl}_{3}-\mathrm{MeOH}, 9: 1\right.$ to $\left.1: 9, \mathrm{v} / \mathrm{v}\right)$ to yield $4(29.0 \mathrm{mg})$. Fraction F13 (800 mg) was applied to RP-C 18 $\mathrm{CC}\left(\mathrm{MeOH}-\mathrm{CH}_{3} \mathrm{CN}\right.$-water, $1: 1: 2$ to $1: 1: 0$, v/v), affording 7 (2.0 mg). Subfraction F1304 (15.5 mg) was purified by preparative HPLC (YMC-Triart $\mathrm{C} 18, \mathrm{CH}_{3} \mathrm{CN}$-water, 1:1, v/v, $4 \mathrm{~mL} / \mathrm{min}$, UV $280 \mathrm{~nm})$ to yield $5\left(t_{\mathrm{R}} 20.5 \mathrm{~min}, 5.5 \mathrm{mg}\right)$. Fraction F14 (1.18 g) was subjected to RP-C ${ }_{18} \mathrm{CC}(\mathrm{MeOH}$-water, $1: 1$ to $2: 1, \mathrm{v} / \mathrm{v})$, affording $6(38.7 \mathrm{mg})$.

2.4. Preparation of Sample and Standard Solutions. Dried flowers of ADC (30 g), NW (30 g), and CM (30 g) were extracted three times with $95 \% \mathrm{EtOH}(200 \mathrm{~mL})$ for $24 \mathrm{~h}$ at room temperature, respectively. The extracted solutions were filtered through filter paper and evaporated in vacuo to afford dryness to each (ADC, $6.27 \mathrm{~g}$, w/w 20.9\%; NW, $7.96 \mathrm{~g}$, w/w 26.53\%; CM, $9.93 \mathrm{~g}$, w/w 33.1\%). All 95\% EtOH extracts were weighed accurately and dissolved in $\mathrm{MeOH}$ at $10 \mathrm{mg} / \mathrm{mL}$. The sample solution was filtered through a syringe filter $(0.45 \mu \mathrm{m})$ for HPLC analysis. The standards were weighed accurately and dissolved in $\mathrm{MeOH}$ at $1.0 \mathrm{mg} / \mathrm{mL}$. The stock solutions were diluted to yield a series of standard solutions at four different concentrations $(25,50,75$, and $100 \mu \mathrm{g} / \mathrm{mL})$ for quantitative analysis.

2.5. Analysis of Phenolic Compounds. Quantitative analysis was conducted using the Agilent 1200 series LC system coupled online with an Agilent 6120 quadrupole single mass spectrometer detector. Data acquisition and processing were performed using the ChemStation software, with an YMCTriart C18 column $(5 \mu \mathrm{m}, 250 \mathrm{~mm} \times 4.6 \mathrm{~mm}$, YMC Co.). Binary gradient elution with $0.1 \%$ formic acid in water $(\mathrm{v} / \mathrm{v}$, solvent $\mathrm{A}$ ) and $0.1 \%$ formic acid in acetonitrile (v/v, solvent $\mathrm{B})$ was performed as follows: $0-60 \mathrm{~min}, 15-35 \% \mathrm{~B} ; 60-70 \mathrm{~min}$, 35-60\% B; 70-71 min, 60-95\% B; 71-80 min, 95\% B; 80$81 \mathrm{~min}, 95-15 \% \mathrm{~B} ; 81-90 \mathrm{~min}, 15 \% \mathrm{~B}$. The total flow rate was maintained at $0.8 \mathrm{ml} / \mathrm{min}$ and the injection volume was $10 \mu \mathrm{L}$. Chromatograms were acquired at 265, 280, 330, and $360 \mathrm{~nm}$ by the DAD detector. Mass spectra were measured between $\mathrm{m} / z 100$ and 1000 in positive ionization mode $\left(\mathrm{ESI}^{+}\right)$at a scan rate of $1.06 \mathrm{sec} / \mathrm{cycle}$ and was monitored by a diode array detector. The mass spectrometric conditions were as follows: capillary voltage $=4000 \mathrm{~V}$; drying gas flow $=10 \mathrm{~L} / \mathrm{min}\left(\mathrm{N}_{2}\right)$; nebulizer pressure $=30$ psig; drying gas temperature $=350^{\circ} \mathrm{C}$.

2.6. Evaluation of Antioxidant Activity. Antioxidant activities of the flowers were measured using the following assays.

2.6.1. DPPH Free Radical Scavenging Activity. The DPPH of the $95 \% \mathrm{EtOH}$ extract of each plant materials was determined by Brand-Williams's method [9]. Briefly, each extract was suspended in DMSO and $100 \mu \mathrm{L}$ of the sample was reacted with $100 \mu \mathrm{L}$ of $0.2 \mathrm{mM}$ DPPH solution. Absorbance measurements were taken $30 \mathrm{~min}$ after the reaction at $517 \mathrm{~nm}$ using an ELISA reader (Benchmark Plus, Bio-Rad, Hercules, CA, USA). The concentration of the extract was calculated from the log-dose inhibition curve for $50 \%$ inhibition of free radicals $\left(\mathrm{SC}_{50}\right)$.

2.6.2. ABTS Radical Cation Scavenging Activity. The ABTS of the $95 \% \mathrm{EtOH}$ extract of each type of plant and the solvent fractions of ADC was evaluated using the method published by Re et al. [10]. In brief, the ABTS was measured by preformed radical monocation. The mixtures, along with $7.4 \mathrm{mM}$ ABTS solution and $2.6 \mathrm{mM}$ potassium persulfate, were incubated at room temperature in the dark for 24 hours. The ABTS solution was diluted with phosphate-buffered saline $(\mathrm{pH} 7.4)$ to achieve an absorbance of $0.7 \pm 0.03$ at $732 \mathrm{~nm}$. Each of the samples was suspended in DMSO and $50 \mu \mathrm{L}$ of the sample was reacted with $950 \mu \mathrm{L}$ of the ABTS solution. Absorbance was taken $10 \mathrm{~min}$ after the reaction at $732 \mathrm{~nm}$ using an ELISA reader (Benchmark Plus, Bio-Rad, Hercules). The concentration of the extract was calculated from the log-dose inhibition curve for $50 \%$ inhibition of free radicals $\left(\mathrm{SC}_{50}\right)$.

2.7. Statistical Analysis. Each experiment was done in triplicate and all data are presented as the mean \pm standard deviation (SD). Statistical differences were determined using Student's $t$-test. The significant level was set at $p<0.05$.

\section{Results and Discussion}

The 95\% ethanol extract of ADC, NW, and CM were evaluated for their antioxidant activity using the ATBS and DPPH radical scavenging assays. As shown in Table 1, ADC extract showed higher radical scavenging activity than did NW and CM extract. Therefore, ADC extract was sequentially partitioned with $n$-hexane, chloroform, ethyl acetate, and $n$ butanol and the solvent fractions were also tested for their ABTS radical scavenging activities (Table 1). Among those tested, the ethyl acetate-soluble fraction of ADC exhibited potent inhibitory activity, with an $\mathrm{SC}_{50}$ value of $42.84 \mu \mathrm{g} / \mathrm{mL}$, and it was further subjected to bioactivity-guided fractionation for the isolation of active lead compounds. The antioxidant activity of ADC could presumably be attributed to certain antioxidant components, for instance, phenolic compounds, which has a wide range of health benefits [11].

To find out the different phytochemical profiles among ADC, NW, and CM depending on their activities, HPLCDAD-ESIMS analysis was performed on standards and samples of each $95 \%$ ethanol extract of the three flowers. 

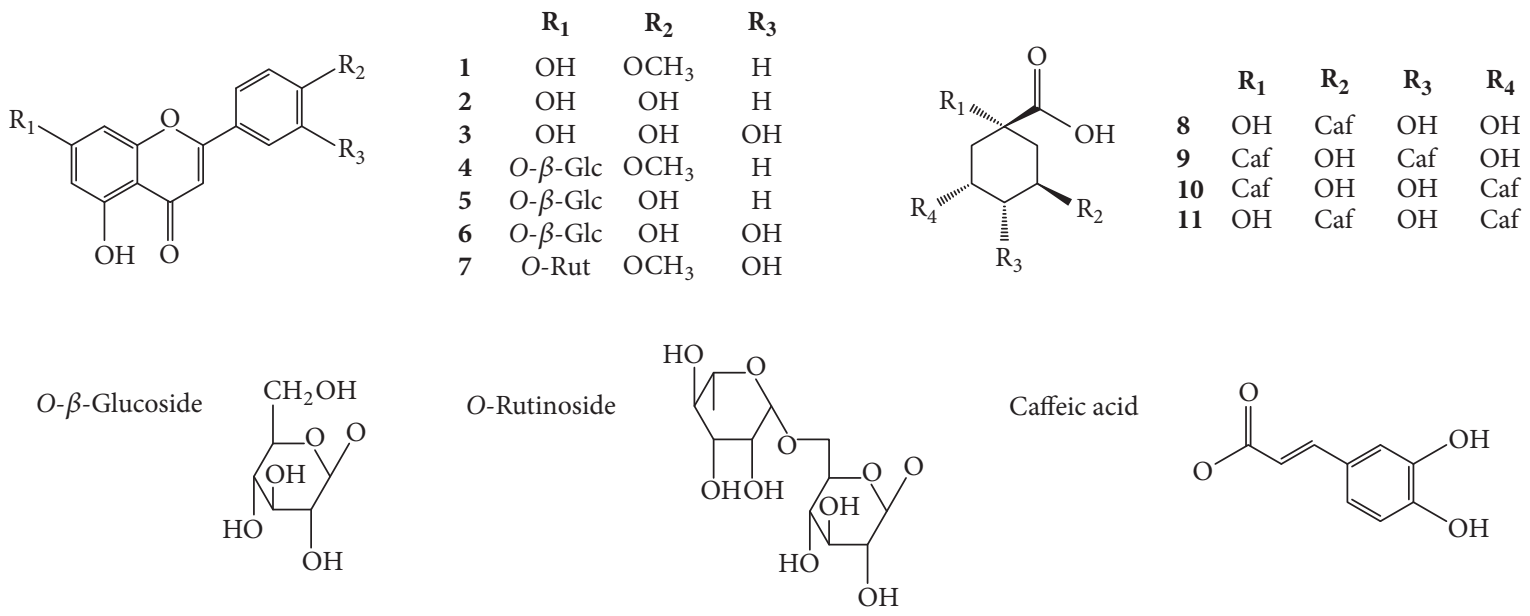

FIGURE 2: Chemical structures of compounds found in ADC flowers.

TABLE 1: Antioxidant activities of the extracts and fractions.

\begin{tabular}{|c|c|c|}
\hline Sample & $\operatorname{ABTS}\left(\mathrm{SC}_{50}, \mu \mathrm{g} / \mathrm{ml}\right)$ & $\mathrm{DPPH}\left(\mathrm{SC}_{50}, \mu \mathrm{g} / \mathrm{ml}\right)$ \\
\hline $95 \%$ ethanol extract of CM & $573.74 \pm 36.16$ & $1904.20 \pm 36.71$ \\
\hline $95 \%$ ethanol extract of $\mathrm{NW}$ & $1156.00 \pm 78.10$ & $1844.82 \pm 72.38$ \\
\hline $95 \%$ ethanol extract of ADC & $272.32 \pm 14.76$ & $960.24 \pm 39.63$ \\
\hline Hexane fraction of ADC & $1464.89 \pm 39.90$ & NT \\
\hline Chloroform fraction of ADC & $282.89 \pm 11.00$ & NT \\
\hline Ethyl acetate fraction of ADC & $42.84 \pm 1.10$ & NT \\
\hline$n$-Butanol fraction of ADC & $269.88 \pm 5.75$ & NT \\
\hline Aqueous fraction of $\mathrm{ADC}$ & $1489.12 \pm 44.74$ & NT \\
\hline Ascorbic acid & $16.68 \pm 1.05$ & $4.67 \pm 0.12$ \\
\hline
\end{tabular}

Values (mean \pm SD) of extracts and fractions analyzed individually in triplicate; ascorbic acid was used as a positive control; NT: not tested.

Seven compounds were isolated from the ethyl acetate fraction of ADC and were identified as acacetin (1) [12], apigenin (2) [13], luteolin (3) [14], acacetin-7-O- $\beta$-glucoside (4) [13], apigenin-7-O- $\beta$-glucoside (5) [14], luteolin-7-O- $\beta$ glucoside (6) [14], and linarin (acacetin-7-O-rutinoside, 7) [15], by analysis of their spectroscopic data as well as by comparison of their data with published values (Figure 2). Peaks for these compounds in HPLC-DAD spectrum were comprehensively determined by comparing their retention times and by coinjection of each sample with standards. (Figure 3; see Figure S1 in Supplementary Material available online at https://doi.org/10.1155/2017/1254721). Peaks 1 and 3 were assigned to chlorogenic acid and dicaffeoylquinic acids by ESI-MS analysis and by comparison with the authentic standards. Their mass ions were readily observed using total ion chromatography (Figures 3 and S2). Peak $1\left(t_{\mathrm{R}} 9.5\right)$ gave a molecular ion peak at $\mathrm{m} / z 355.1[\mathrm{M}+\mathrm{H}]^{+}$and the fragmental mass ion of caffeic acid at $m / z 163.0$ [M-quinic acid] ${ }^{+}$in its mass spectrum, corresponding to chlorogenic acid (8). Peak $3\left(t_{\mathrm{R}} 30.6\right)$ demonstrated a molecular ion peak at $\mathrm{m} / z$ $517.1[\mathrm{M}+\mathrm{H}]^{+}$and fragmental mass ions at $\mathrm{m} / z$ 499.1 [M$\left.\mathrm{H}_{2} \mathrm{O}\right]^{+}$and 163.1 [M-caffeoylquinic acid] ${ }^{+}$, indicating dicaffeoylquinic acids (DCQA). There are six positional isomers of DCQAs, such as 1,3-, 1,4-, 1,5-, 3,4-, 3,5-, and 4,5-DCQAs [16], and they are available from commercial suppliers. By comparing their retention times with those of authentic standards, peak at $t_{\mathrm{R}} 30.6$ was identified as a mixture of three compounds, 1,4-DCQA (9), 1,5-DCQA (10), and 3,5-DCQA (11), which showed the same retention time in the chromatograms. Other standards, 1,3-, 3,4-, and 4,5-DCQAs, were not detected by total ion chromatography. As a result, nine peaks (peaks 1-9) have been detected, of which the identities and properties are summarized in Table 2.

A quantitative analysis of flavonoids and phenolic acids found in ADC was performed using HPLC-DAD-ESIMS. The established method is described in Section 2.5. HPLCDAD-ESIMS chromatograms of the 95\% ethanol extract of the three flowers and the standard solution are shown in Figure 3 and data for each peak are listed in Table 2. The linear relationships between the peak areas $(y)$ and concentrations $(x, \mu \mathrm{g} / \mathrm{ml})$ of the compounds were calculated by regression equations $(y=a x+b$; $a$ : slope; $b$ : intercept). The calibration curves showed a high degree of linearity with a correlation coefficient of $r^{2}>0.999$ over the concentration range $25-100 \mu \mathrm{g} / \mathrm{ml}$. The limits of detection (LOD) and limits of quantification (LOQ) for the 8 compounds and a mixture of 9-11 were in the range of $0.057-0.716 \mu \mathrm{g} / \mathrm{ml}$ and $0.173-2.168 \mu \mathrm{g} / \mathrm{ml}$, respectively. This analytical method 




$\square$ DAD1 B, Sig = 280, 4 Ref = off (HAR-161208 2016-12-07 17-58-12\001-0101.D)

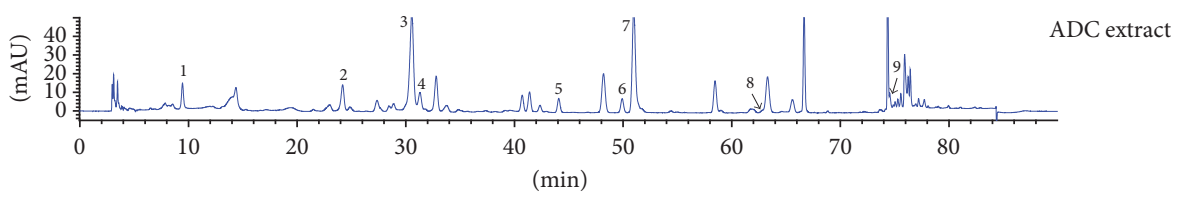

$\square$ DAD1 B, Sig $=280,4$ Ref $=$ off (HAR-161208 2016-12-07 17-58-12\003-0301.D)

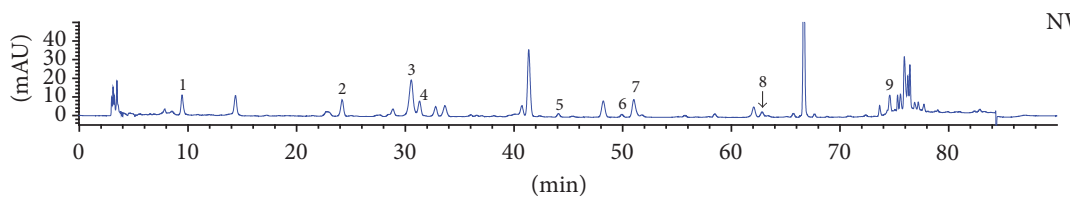

NW extract

$\square$ DAD1 B, Sig = 280, 4 Ref = off (HAR-161208 2016-12-07 17-58-12\004-0401.D)

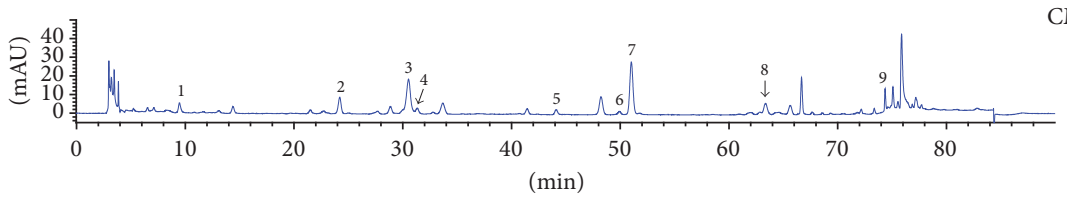

$\square$ DAD1 B, Sig = 280, 4 Ref = off (HAR-161208 2016-12-07 17-58-12\005-0501.D)

(a)

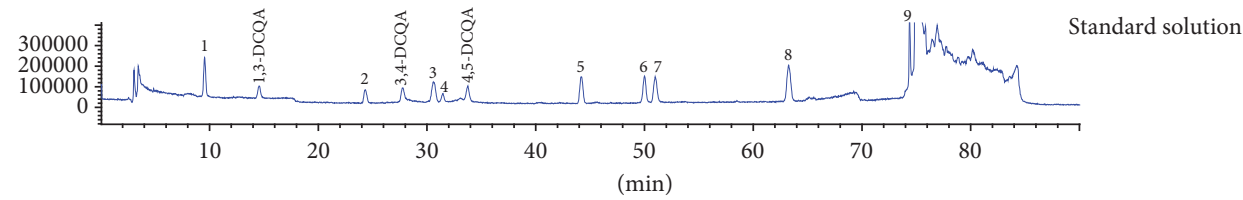

$\square$ MSD1 TIC, MS File (C:ICHEM32\I\DATA\HAR-161208 2016-12-07 17-58-12\001-0101.D) ES-API, Pos, Scan, Frag: 100

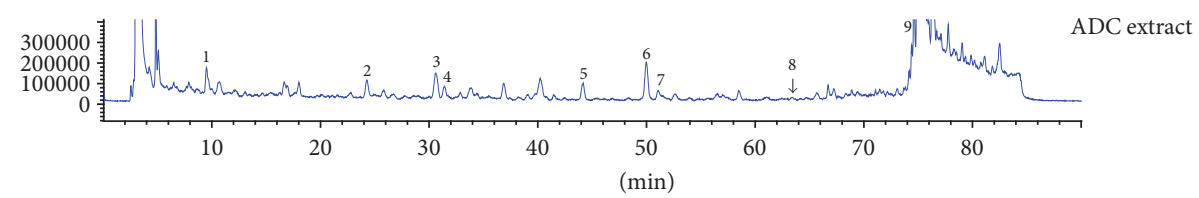

$\square$ MSD1 TIC, MS File (C:ICHEM32\\\DATA\HAR-161208 2016-12-07 17-58-12\006-0601.D) ES-API, Pos, Scan, Frag: 100

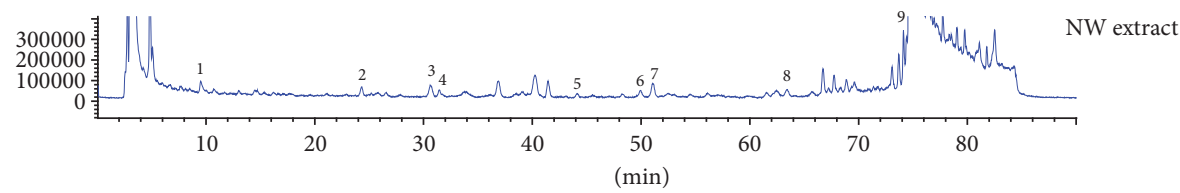

$\square$ MSD1 TIC, MS File (C:ICHEM32\1\DATA\HAR-161208 2016-12-07 17-58-12\007-0701.D) ES-API, Pos, Scan, Frag: 100

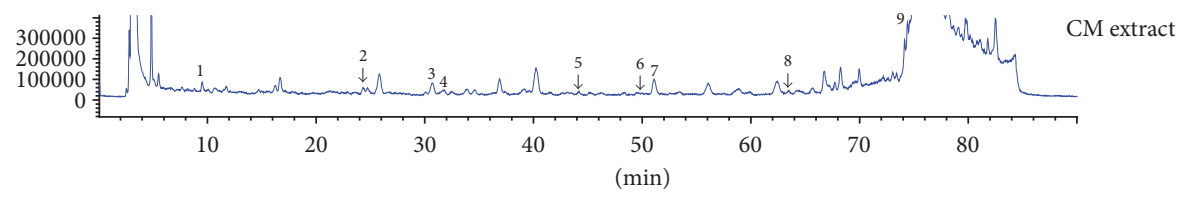

$\square$ MSD1 TIC, MS File (C:ICHEM32\1\DATA \HAR-161208 2016-12-07 17-58-12\008-0801.D) ES-API, Pos, Scan, Frag: 100

(b)

Figure 3: (a) HPLC chromatograms at $280 \mathrm{~nm}$ and (b) the expansion of total ion chromatograms in the positive ion mode. For the identification of each numbered peak, see Table 2. 
TABLE 2: Identification and mass spectrometric properties of the phenolic compounds from chrysanthemum cultivars.

\begin{tabular}{lccccc}
\hline Peak & $t_{\mathrm{R}}(\mathrm{min})$ & $\lambda_{\max }(\mathrm{nm})$ & {$[\mathrm{M}]^{+}(\mathrm{m} / z)$} & $\mathrm{MS}^{n}(\mathrm{~m} / z)$ & Compound \\
\hline 1 & 9.51 & 220,325 & 355.1 & 163.0 & - \\
2 & 24.27 & $255,270,350$ & 449.1 & $499.1 / 163.1$ & Chlorogenic acid (8) \\
3 & 30.61 & 220,325 & 517.1 & - & Mixture of 1,4-, 1,5-, and 3,5-DCQAs (9-11) \\
4 & 31.39 & 265,340 & 433.1 & - & Apigenin-7-O- $\beta$-glucoside (5) \\
5 & 44.18 & 265,330 & 593.2 & - & Linarin (7) \\
6 & 49.98 & 265,330 & 447.1 & 223.1 & Acacetin-7-O- $\beta$-glucoside (4) \\
7 & 51.08 & 265,350 & 287.0 & - & Luteolin (3) \\
8 & 63.41 & $250,260,350$ & 271.1 & Apigenin (2) \\
9 & 74.42 & 265,335 & 285.1 & Acacetin $(\mathbf{1})$ \\
\hline
\end{tabular}

TABLE 3: Linear range, regression equation, correlation coefficients, LODs, and LOQs of the compounds.

\begin{tabular}{lcccc}
\hline Compound & Regression equation & Correlation coefficient $\left(r^{2}\right)$ & $\mathrm{LOD}(\mu \mathrm{g} / \mathrm{mL})$ & $\mathrm{LOQ}(\mu \mathrm{g} / \mathrm{mL})$ \\
\hline Acacetin (1) & $y=11.349 x+2.520$ & 0.9996 & 0.057 & 0.173 \\
Apigenin (2) & $y=36.953 x-46.980$ & 0.9992 & 0.575 & 1.742 \\
Luteolin (3) & $y=23.094 x+5.220$ & 0.9995 & 0.244 & 0.738 \\
Acacetin-7-O- $\beta$-glucoside (4) & $y=14.277 x+20.120$ & 0.9991 & 0.206 & 0.624 \\
Apigenin-7-O- $\beta$-glucoside (5) & $y=33.317 x-9.170$ & 0.9992 & 0.267 & 0.716 \\
Luteolin-7-O- $\beta$-glucoside (6) & $y=14.105 x-16.180$ & 0.9993 & 0.9994 & 0.178 \\
Linarin (7) & $y=21.849 x-21.340$ & 0.9994 & 0.611 \\
Chlorogenic acid (8) & $y=18.675 x-17.907$ & 0.9991 & 0.539 \\
Mixture of 1,4-, 1,5-, and 3,5-DCQAs (9-11) & $y=22.766 x-25.32$ & 1.822 \\
\hline
\end{tabular}

$y=$ peak area, $x=$ concentration $(\mu \mathrm{g} / \mathrm{ml}), a=$ slope, $b=$ intercept; limit of detection (LOD): $3.3 \times(\mathrm{SD}$ of the response/slope of the calibration curve); limit of quantification (LOQ): $10 \times(\mathrm{SD}$ of the response/slope of the calibration curve).

TABLE 4: Contents of compounds 1-8 and a mixture of 9-11 in the three flowers (Mean \pm SD, $n=3$ ).

\begin{tabular}{|c|c|c|c|}
\hline \multirow{2}{*}{ Compound } & \multicolumn{3}{|c|}{ Contents (mg/g) } \\
\hline & $\mathrm{ADC}$ & NW & $\mathrm{CM}$ \\
\hline Acacetin (1) & $0.529 \pm 0.034$ & $0.381 \pm 0.019$ & $0.455 \pm 0.019$ \\
\hline Apigenin (2) & $0.114 \pm 0.004$ & $0.290 \pm 0.012$ & $0.251 \pm 0.018$ \\
\hline Luteolin (3) & $0.348 \pm 0.012$ & $0.577 \pm 0.022$ & $1.171 \pm 0.066$ \\
\hline Acacetin-7-O- $\beta$-glucoside (4) & $2.441 \pm 0.079$ & $0.328 \pm 0.012$ & $0.110 \pm 0.002$ \\
\hline Apigenin-7-O- $\beta$-glucoside (5) & $0.479 \pm 0.010$ & $0.205 \pm 0.004$ & $0.076 \pm 0.005$ \\
\hline Luteolin-7-O- $\beta$-glucoside (6) & $2.761 \pm 0.032$ & $0.629 \pm 0.010$ & $0.888 \pm 0.103$ \\
\hline Linarin $(7)$ & $0.582 \pm 0.010$ & $0.117 \pm 0.003$ & $0.211 \pm 0.002$ \\
\hline Chlorogenic acid (8) & $0.905 \pm 0.010$ & $0.373 \pm 0.017$ & $0.533 \pm 0.029$ \\
\hline Mixture of 1,4-, 1,5-, and 3,5-DCQAs (9-11) & $4.403 \pm 0.082$ & $0.833 \pm 0.028$ & $1.830 \pm 0.077$ \\
\hline Total phenolic compounds & $12.562 \pm 0.255$ & $3.732 \pm 0.108$ & $5.525 \pm 0.115$ \\
\hline
\end{tabular}

was applied to the simultaneous quantification of the 8 compounds and a mixture of compounds 9-11 from the three flowers, and the results are shown in Table 3. An increase in flavonoid glycosides and phenolic acids and a decrease in flavone aglycones were observed in ADC extract, compared to the extract from NW and CM (Table 4), indicating that radiation-induced mutation breeding enhanced the production of certain active compounds. For examples, apigenin (2) [17], luteolin (3) [18], luteolin-7-O- $\beta$-glucoside (6) [18], chlorogenic acid (8) [19], and 1,5-DCQA (10) [20] have exhibited their antioxidant effects by attenuating the oxidative damage thorough activation of nuclear factorerythroid 2-related factor 2 (Nrf2) pathway. There have also been reports that acacetin-7-O- $\beta$-glucoside (4) showed moderate DPPH radical scavenging activity [21]; however 3,5-DCQA (11) exhibited strong DPPH and ABTS radical scavenging and ferric reducing antioxidant power (FRAP) activities [22]. According to these previous reports, the high content of total phenolic compound in ADC extract was most likely responsible for its antioxidant activity. 
Studies on different types of flavonoids and their known functions inside the plant have reported that flavonoid glycosides were involved in protection against radiation stress and in producing purple pigment [23]. In addition, there have been reports that the generation of caffeoylquinic acids was induced in an anthocyanin-accumulating plant cell line such as a purple sweet potato [24], and eventually the biosynthetic pathway of phenolic compounds can be closely related to that of anthocyanins [25]. Thus, a color change to purple of ADC flower petal was considerably affected by radiation-induced mutagenesis and seems to be mediated by the accumulation of flavonoid glycosides and caffeoylquinic acids.

\section{Conclusion}

In conclusion, the radiation-induced mutant cultivar, ADC extract, exhibited stronger antioxidant activity, compared to the extracts from the control plant, NW, and the medicinal herb, CM. The enhancement of the antioxidant properties of ADC flower extract is due to higher concentrations of antioxidant phenolic compounds. Phenolic profiles determined by HPLC-DAD-ESIMS revealed seven flavonoids and four phenolic acids which were tentatively identified and quantified. Therefore, these results make ADC flowers a very promising source of natural-occurring antioxidants as well as a commercially useful product. Further studies on its processing suitability analysis and detailed mechanism of action in our laboratory are being developed for commercialization of ADC flower as a new purple colored chrysanthemum tea or a dietary supplement.

\section{Conflicts of Interest}

The authors declare no conflicts of interest regarding publication of this paper.

\section{Acknowledgments}

This research was supported by Radiation Technology R\&D Program (no. 2012M2A2A6010575) through the National Research Foundation of Korea (NRF) funded by the Ministry of Science, ICT \& Future Planning.

\section{References}

[1] D. Bensky, S. Clavey, and E. Stöger, Chinese Herbal Medicine: Materia Medica, Eastland Press, Seattle, WA, USA, 3rd edition, 2004.

[2] J.-P. Lai, Y. H. Lim, J. Su, H.-M. Shen, and C. N. Ong, "Identification and characterization of major flavonoids and caffeoylquinic acids in three Compositae plants by LC/DADAPCI/MS," Journal of Chromatography B, vol. 848, no. 2, pp. 215-225, 2007.

[3] H. J. Kim and Y. S. Lee, "Identification of new dicaffeoylquinic acids from Chrysanthemum morifolium and their antioxidant activities," Planta Medica, vol. 71, no. 9, pp. 871-876, 2005.

[4] S. J. Kim, K.-T. Lee, H.-E. Choi et al., "Anti-inflammatory effects of flavonoids in Korean Chrysanthemum species via suppression of inducible nitric oxide synthase and cyclooxygenase- 2 in LPSinduced RAW 264.7 macrophages," Food Science and Biotechnology, vol. 24, no. 3, pp. 975-985, 2015.

[5] Y.-Y. Xie, D. Yuan, J.-Y. Yang, L.-H. Wang, and C.-F. Wu, "Cytotoxic activity of flavonoids from the flowers of chrysanthemum morifolium on human colon cancer Colon205 cells," Journal of Asian Natural Products Research, vol. 11, no. 9, pp. 771-778, 2009.

[6] A. Tanaka, N. Shikazono, and Y. Hase, "Studies on biological effects of ion beams on lethality, molecular nature of mutation, mutation rate, and spectrum of mutation phenotype for mutation breeding in higher plants," Journal of Radiation Research, vol. 51, no. 3, pp. 223-233, 2010.

[7] H. Ali, Z. Ghori, S. Sheikh, and A. Gul, "Effects of gamma radiation on crop production," in Crop Production and Global Enviromental Issues, Springer International Publishing, Cham, Switzerland, 2016.

[8] Y. D. Jo, Y.-S. Kim, J. Ryu, H.-I. Choi, S. W. Kim, H. S. Kang et al., "Deletion of carotenoid cleavage dioxygenase 4a (CmCCD4a) and global up-regulation of plastid protein-coding genes in a mutant chrysanthemum cultivar producing yellow petals," Scientia Horticulturae, vol. 212, pp. 49-59, 2016.

[9] W. Brand-Williams, M. E. Cuvelier, and C. Berset, "Use of a free radical method to evaluate antioxidant activity," LWT-Food Science and Technology, vol. 28, no. 1, pp. 25-30, 1995.

[10] R. Re, N. Pellegrini, A. Proteggente, A. Pannala, M. Yang, and C. Rice-Evans, "Antioxidant activity applying an improved ABTS radical cation decolorization assay," Free Radical Biology \& Medicine, vol. 26, no. 9-10, pp. 1231-1237, 1999.

[11] L. H. Yao, Y. M. Jiang, J. Shi et al., "Flavonoids in food and their health benefits," Plant Foods for Human Nutrition, vol. 59, no. 3, pp. 113-122, 2004.

[12] X. Wang, H. Perumalsamy, H. W. Kwon, Y.-E. Na, and Y.-J. Ahn, "Effects and possible mechanisms of action of acacetin on the behavior and eye morphology of Drosophila models of Alzheimer's disease," Scientific Reports, vol. 5, Article ID 16127, pp. 1-21, 2015.

[13] T. Ersöz, Ü. Ş. Harput, İ. Saracoğlu, and İ. Çalisp, "Phenolic Compounds from scutellaria pontica," Turkey Journal of Chemistry, vol. 26, no. 4, pp. 581-588, 2002.

[14] Y.-L. Li, J. Li, N.-L. Wang, and X.-S. Yao, "Flavonoids and a new polyacetylene from Bidens parviflora Willd," Molecules, vol. 13, no. 8, pp. 1931-1941, 2008.

[15] S.-J. Kim, H.-I. Cho, S.-J. Kim et al., "Protective effect of linarin against d-galactosamine and lipopolysaccharide-induced fulminant hepatic failure," European Journal of Pharmacology, vol. 738, pp. 66-73, 2014.

[16] L. Zhang, Z.-C. Tu, H. Wang, Q.-H. Wen, Z.-F. Fu, and X. Xie, "Antioxidant activity and phenolic acids profiles of artemisia selengensis turcz extracted with various methods by HPLCqTOF-MS/MS," Journal of Food Biochemistry, vol. 40, no. 4, pp. 603-612, 2016.

[17] X. Xu, M. Li, W. Chen, H. Yu, Y. Yang, and L. Hang, "Attenuates oxidative injury in ARPE-19 cells thorough activation of Nrf2 pathway," Oxidative Medicine and Cellular Longevity, vol. 2016, Article ID 4378461, 2016.

[18] Y. S. Song and C. M. Park, "Luteolin and luteolin-7-O-glucoside strengthen antioxidative potential through the modulation of Nrf2/MAPK mediated HO-1 signaling cascade in RAW 264.7 cells," Food and Chemical Toxicology, vol. 65, pp. 70-75, 2014.

[19] L. Chen, Y. Li, W. Yin et al., "Combination of chlorogenic acid and salvianolic acid B protects against polychlorinated 
biphenyls-induced oxidative stress through Nrf2," Environmental Toxicology and Pharmacology, vol. 46, pp. 255-263, 2016.

[20] X. Cao, H. Xiao, Y. Zhang, L. Zou, Y. Chu, and X. Chu, "1,5Dicaffeoylquinic acid-mediated glutathione synthesis through activation of Nrf2 protects against OGD/reperfusion-induced oxidative stress in astrocytes," Brain Research, vol. 1347, pp. 142148, 2010.

[21] A. K. Sahoo, N. Narayanan, S. Rajan, and P. K. Mukherjee, "A flavonoid glycoside from the leaves of Morinda tinctoria," Natural Product Communications, vol. 3, no. 9, pp. 1495-1496, 2008.

[22] S. Hong, T. Joo, and J.-W. Jhoo, "Antioxidant and anti-inflammatory activities of 3,5-dicaffeoylquinic acid isolated from Ligularia fischeri leaves," Food Science and Biotechnology, vol. 24, no. 1, pp. 257-263, 2015.

[23] B. Winkel-Shirley, "Biosynthesis of flavonoids and effects of stress," Current Opinion in Plant Biology, vol. 5, no. 3, pp. 218223, 2002.

[24] I. Konczak, S. Okuno, M. Yoshimoto, and O. Yamakawa, "Caffeoylquinic acids generated in vitro in a high-anthocyaninaccumulating sweet potato cell line," Journal of Biomedicine and Biotechnology, vol. 2004, no. 5, pp. 287-292, 2004.

[25] E. Haslam, Practical Polyphenolics. from Structure to Molecular Recognition And Physiological Action, Cambridge University Press, Cambridge, UK, 1998. 

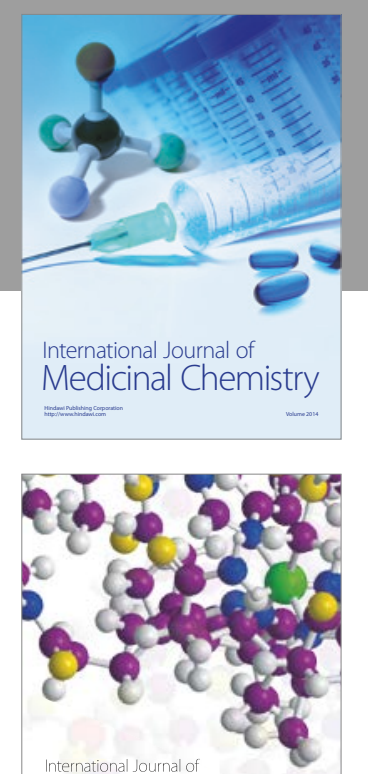

Carbohydrate Chemistry

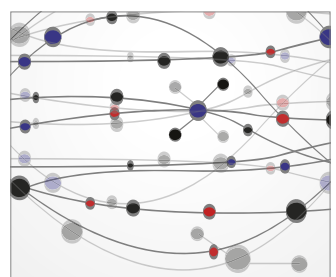

The Scientific World Journal
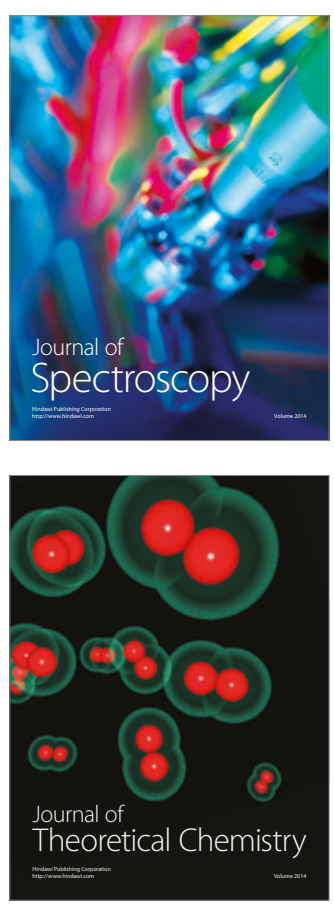
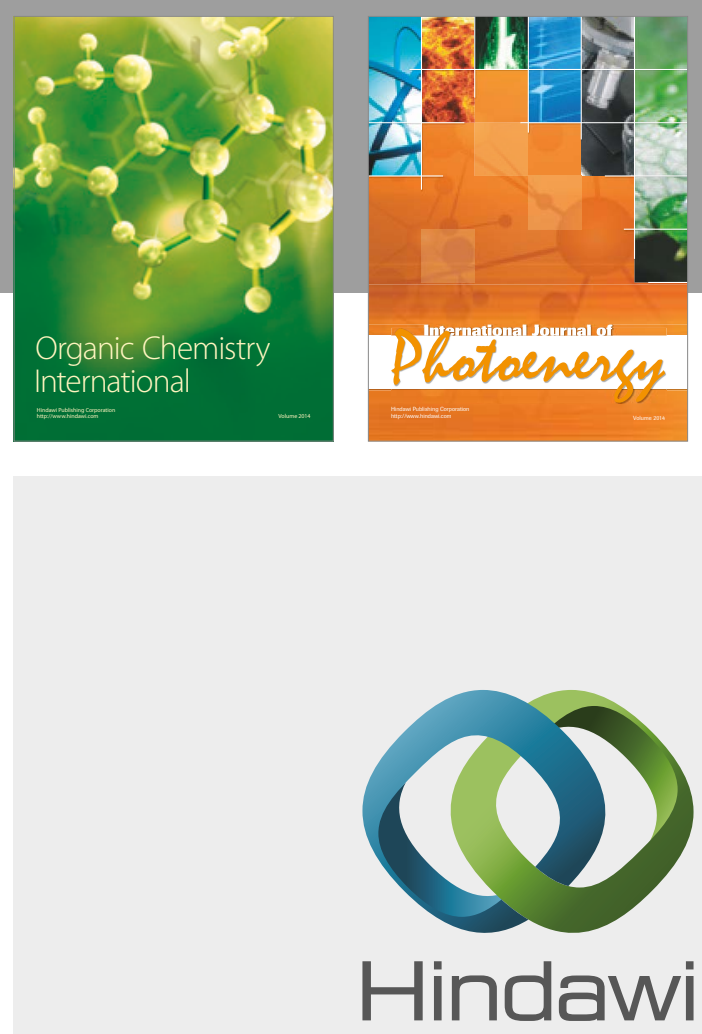

Submit your manuscripts at

https://www.hindawi.com

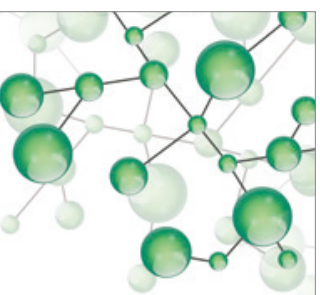

International Journal of

Inorganic Chemistry

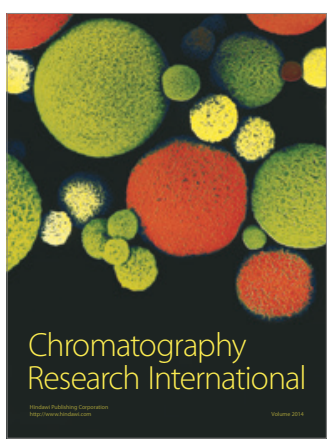

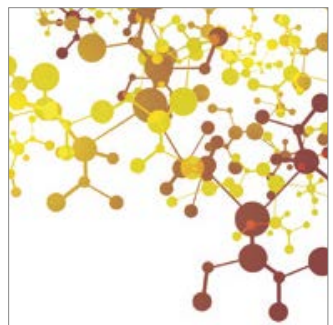

Applied Chemistry
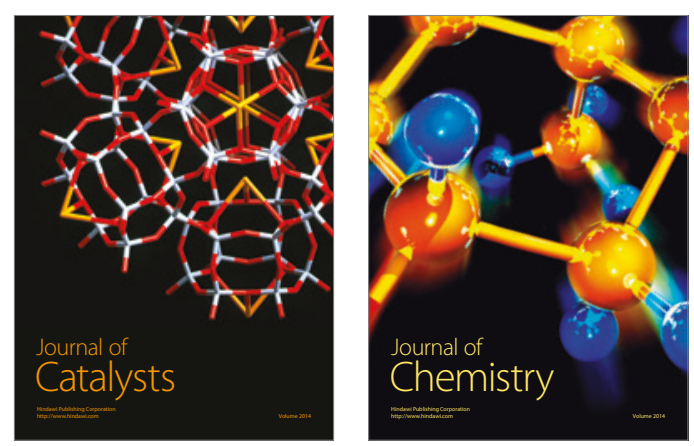
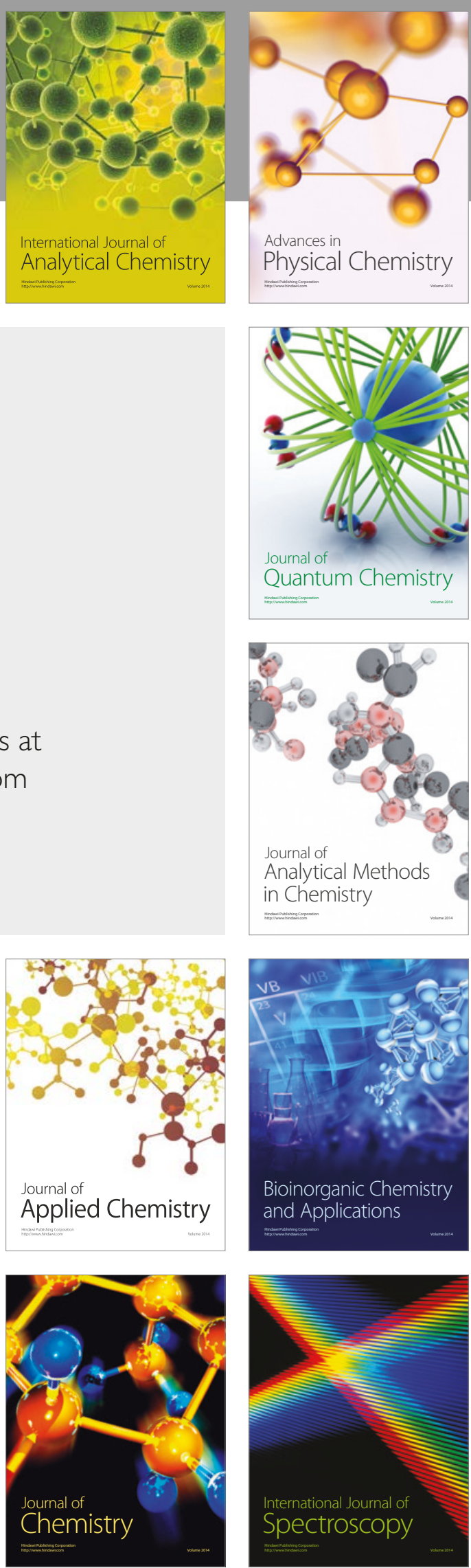